Original Research Article

\title{
A descriptive study on drug prescribing pattern in hypertensive patients in a tertiary care teaching hospital
}

\author{
Syed Sajad Hussain*, Samina Farhat, Parvaiz Ahmad Zargar, Zorawar Singh Bali
}

Department of Pharmacology, Government Medical College, Srinagar, Jammu and Kashmir, India

Received: 22 August 2017

Revised: 30 August 2017

Accepted: 21 September 2017

*Correspondence to:

Dr. Syed Sajad Hussain,

Email: sajadsafvi@gmail.com

Copyright: (C) the author(s), publisher and licensee Medip Academy. This is an openaccess article distributed under the terms of the Creative Commons Attribution NonCommercial License, which permits unrestricted noncommercial use, distribution, and reproduction in any medium, provided the original work is properly cited.

\begin{abstract}
Background: Hypertension is highly prevalent and the goal of antihypertensive therapy is to abolish the risks associated with blood pressure (BP) elevation without adversely affecting quality of life. Drug selection is based on efficacy in lowering BP and in reducing cardiovascular $(\mathrm{CV})$ end points including stroke, myocardial infarction, and heart failure. Not many studies are conducted in this part of world regarding drug utilization of antihypertensive drugs and hence this study was planned.
\end{abstract}

Methods: A descriptive cross-sectional study was conducted for a period 6 month in outpatient department of a tertiary care centre of Government Medical College, Srinagar, Jammu and Kashmir. The prescriptions containing antihypertensive drugs were collected from the patients attending the outpatient department.

Results: During the study period a total of 230 prescriptions were collected, out of which 196 were included for the final analysis. Mean age was found to be $62.42 \pm 7.77$ years. In majority of cases (44.89\%), a combination of two drugs was prescribed and among the two-drug combination, Angiotensin Receptor Blockers (ARBs) and Calcium Channel Blockers (CCBs) were used most commonly (40.90\%). Angiotension receptor blockers were used as single drug in most number of patients (41.66\%). Proton pump inhibitors were the most common $(35.71 \%)$ co-prescribed drug, followed by Anti platelet drugs (27.55\%), Anti diabetics $(16.32 \%)$ and Statins (16.32).

Conclusions: Present study represents the current prescribing trend for antihypertensive agents. It implies that ARBs are the leading group of antihypertensive agents both when used singly and in combination. Further studies focused on the rationale for choice of drugs based on demographic data, economic status, associated comorbid conditions and complications would give additional insights into prescribing patterns in hypertension in India.

Keywords: Anti-hypertensive drugs, Drug utilization, Prescribing pattern

\section{INTRODUCTION}

Hypertension is a disease of complex etiology, affecting 972 million people worldwide. Prevalence of hypertension in India is reported to vary from 4 to $15 \%$ in urban and 2 $8 \%$ in rural population. ${ }^{1}$ It is a leading risk factor for coronary heart disease, stroke and chronic renal disease. Evidence from large clinical trials now suggests that lowering blood pressure effectively prevents these adverse outcomes. ${ }^{2,3}$ Selection of antihypertensive agents should therefore be based primarily on their comparative ability to prevent these complications. Therefore, it is important that once the diagnosis of hypertension is established, blood pressure should be controlled adequately through regular follow-up, lifestyle modification, exercise and effective antihypertensive drugs. ${ }^{4}$

Drug utilization studies which evaluate and analyze the drug therapy in hypertension and hypertension associated diseases is very essential from time to time to observe the prescribing attitude of physicians with the aim of rational use of drugs and to minimize the adverse drug reactions. ${ }^{5,6}$ 
In consideration of all these facts, the present study was designed to analyze the prescribing patterns of antihypertensive drugs in a tertiary care teaching hospital in Srinagar, Jammu and Kashmir.

\section{METHODS}

This was a cross sectional descriptive study conducted by the department of Pharmacology in the outpatient Department of General Medicine of Sheri Maharaja Heri Singh (SMHS) Hospital, which is one of the tertiary care teaching hospital associated with Government Medical College, Srinagar. The period of the present study was 6months. A total of 230 prescriptions were collected, out of which a 196 were included for the final analysis.

\section{Inclusion criteria}

- Patients diagnosed with hypertension according to the Joint National Committee (JNC) 7 guidelines.

- Patients with any stage of hypertension with or without any co-morbid disease.

- Patients of either gender.

- Patients above 18 years of age.

\section{Exclusion criteria}

- $\quad$ Patients who did not met the inclusion criteria.

- Pregnant women of any age group.

The patients were diagnosed and treated by consultant specialist of medicine and the prescriptions containing anti-hypertensive drugs were collected from the patients attending the outpatient department of general medicine. The patient's demographics, blood Pressure, antihypertensive drugs prescribed, comorbid conditions were entered in a specially designed proforma. The statistical analysis of collected data was performed by using the latest version of SPSS and the results were formulated.

\section{RESULTS}

During the study period a total of 230 prescriptions were collected, out of which a 196 were included for the final analysis. The females dominated the male population and comprised $57.10 \%$ of the total participants. The age of the patients varied from 40 to 78 years and the majority of the participants were of 60-69 years age group, forming $53.10 \%$ of total study population. The mean age was found to be $62.42 \pm 7.77$ years. The studied patients were mostly of urban origin $(59.20 \%)$ than rural $(39.80 \%)$. The majority of our patients $(95 \%)$ presented with one or more comorbid diseases, among which Diabetes Miletus was the most common comorbid disease $(23.46 \%)$ followed by post pacemaker status $(10.20 \%)$, hypertensive heart disease $(9.18 \%)$ and sub clinical hypothyroidism $(9.18 \%)$. When the data was analysed by virtue of the number of antihypertensive drugs used, it was observed that in majority of cases $(44.89 \%)$, a combination of two drugs was prescribed, followed by three drug combination which was used in $16.32 \%$ of patients, as has been shown in Table 1. When it comes to use of single drug for controlling the hypertension it was found that only $12.24 \%$ of patients could be controlled by a single drug treatment. Among the two-drug combination, angiotensin receptor blocker (ARB) and calcium channel blocker (CCB) combination was the most common $(40.90 \%)$.

Table 1: Number of antihypertensive drugs and the percentage of their utilization.

\begin{tabular}{|ll|}
\hline $\begin{array}{l}\text { Number of antihypertensive } \\
\text { drugs used }\end{array}$ & $\begin{array}{l}\text { Number of } \\
\text { patients }(\%)\end{array}$ \\
\hline Single drug & $24(12.24)$ \\
\hline Two drugs & $88(44.89)$ \\
\hline Three drugs & $32(16.32)$ \\
\hline Four drugs & $42(21.42)$ \\
\hline More than four drugs & $10(5.10)$ \\
\hline Total & $196(100)$ \\
\hline
\end{tabular}

Table 2: Type of antihypertensive drugs used and the percentage of their utilization.

\begin{tabular}{|c|c|c|}
\hline $\begin{array}{l}\text { Number of } \\
\text { antihypertensive } \\
\text { drugs }\end{array}$ & $\begin{array}{l}\text { Type of } \\
\text { antihypertensive } \\
\text { drugs }\end{array}$ & $\begin{array}{l}\text { Number } \\
(\%)\end{array}$ \\
\hline \multirow{4}{*}{ Single drug } & ARBs & $10(41.66)$ \\
\hline & BBs & $8(33.33)$ \\
\hline & CCBs & $4(16.66)$ \\
\hline & ACE inhibitors & $2(8.33)$ \\
\hline Total & & $24(100)$ \\
\hline \multirow{5}{*}{$\begin{array}{l}\text { Two drug } \\
\text { combinations }\end{array}$} & $\mathrm{ARBs}+\mathrm{CCBs}$ & $36(40.90)$ \\
\hline & ARBs+ TZDUs & $26(29.54)$ \\
\hline & $\mathrm{CCBs}+\mathrm{BBs}$ & $14(15.90)$ \\
\hline & $\mathrm{ARBs}+\mathrm{BBs}$ & $8(9.09)$ \\
\hline & $\begin{array}{l}\text { AC inhibitors }+ \\
\text { BBs }\end{array}$ & $6(6.81)$ \\
\hline Total & & $88(100)$ \\
\hline \multirow{3}{*}{$\begin{array}{l}\text { Three drug } \\
\text { combination }\end{array}$} & $\begin{array}{l}\text { ARBs +TZDUs + } \\
\text { BBs }\end{array}$ & $14(43.75)$ \\
\hline & $\begin{array}{l}\mathrm{ARBs}+\mathrm{CCBs}+ \\
\mathrm{BBs}\end{array}$ & $12(37.55)$ \\
\hline & $\begin{array}{l}\text { TZDUs + BBs + } \\
\text { CCBs }\end{array}$ & $6(18.75)$ \\
\hline Total & & $32(100)$ \\
\hline
\end{tabular}

ARBs: angiotensin receptor blockers, BBs: Beta blockers, CCBs: Calcium channel blockers, ACE inhibitors: Angiotensin converting enzyme inhibitors, TZDUs: Thiazide type diuretics

The combination of ARBs and thiazide type diuretics (TTDs) was prescribed in $29.54 \%$ of patients followed by combination of CCBs and beta blockers (BBs) which was used in $15.90 \%$ cases, the same has been depicted in Table 2. During the study it was observed that four drug regimens was prescribed in $21.42 \%$ of total participants and the combination of four front line antihypertensive drug classes comprising of ARBs, TTDs, CCBs and BBs was 
used in most instances $(61.90 \%)$. When three drug combination regimens was analysed, the combination of ARBs, TTDs and BBs was used in most instances $(46.66 \%)$. Angiotension receptor blockers were used as single drug in most number of patients $(41.66 \%)$, followed by BBs $(33.33 \%)$ and CCBs $(16.66 \%)$. It was interesting to find that in $5.10 \%$ of our studied population more than four drugs were combined together which included the addition of Potassium sparing diuretics to a ARB, BB, $\mathrm{CCB}$ and TTD type diuretics in most instances.

During the study period it was found that many different classes of drugs were co-prescribed along with antihypertensive drugs. Proton pump inhibitors were the most common $(35.71 \%$ ) co-prescribed drug, followed by antiplatlet drugs $(27.55 \%)$, anti-diabetics $(16.32 \%)$ and Statins (16.32).

\section{DISCUSSION}

Drug utilization studies are one of the most effective methods used to assess the prescribing pattern of different drugs by physicians. ${ }^{7}$ These studies are supposed to be powerful exploratory tools to ascertain the role of drugs in society. ${ }^{8}$ They have been found to create a sound sociomedical and health economic basis for health care decision making. ${ }^{9}$

During the present study it was observed that incidence of hypertension was higher in females, that was comparable to the earlier studies conducted on hypertensive patients by Tiwari et al in India, Pittrow et al, in Germany and Lee et al, in China. ${ }^{10-12}$ Most of the patients were in the age group of 60-69 years and the mean age was $62.42 \pm 7.77$ years among both the genders. This could be due to the fact that hypertension is very common in this age group. Similar (The above same) observations were also noticed in a study conducted in India by Hari Babu et al. ${ }^{13}$ In the present study it was observed that most commonly prescribed single drug antihypertensive agents were angiotensin receptor blockers, which was comparable with a previous study by Elliott WJ et al. ${ }^{14}$ Since diabetes mellitus was one of the most prevalent coexisting disease, the prescription of ARBs seems justified as these drugs have a protective role in diabetic patients. These drugs are known to decrease the onset and progress of micro vascular complication of hypertension and diabetes mellitus as described in previous studies. ${ }^{15}$

An ideal combination therapy is one which must include antihypertensive drugs possessing complementary modes of action and having synergistic anti-hypertensive effects without or with minimum adverse effects, at low doses. ${ }^{10}$ In the present study two drug combination therapy was most commonly prescribed than other combinations, which was comparable with other study conducted by Pia et al. ${ }^{16}$ The two drug antihypertensive therapy used in the majority of patients may be justified by the fact that in most cases the patients were having some associated comorbid disease and it difficult to achieve the target blood pressure control using a single drug. Although the combination of diuretics and angiotensin receptor blockers is the most common drug combination used in most previous studies, but during the present study, ARBs and CCBs were combined at the most, which may be because of the fact that diuretics are not preferred especially in diabetic patients because of their poor side effect profile. During the present we found that many patients who were put on Thiazide diuretics presented with several vague symptoms that included headache, nausea and vomiting and on biochemical evaluation they were found to have low levels of blood sodium, which also led to lower use of diuretic combination during the present study. The combination of an ARB with a CCB has also been found to result in fully additive BP reduction. ${ }^{17,18}$ Addition of RAAS inhibitors significantly improves the tolerability profile of the CCB. Through their anti-sympathetic effects, RAAS inhibitors blunt the increase in heart rate that may accompany in treatment with a dihydropyridine type CCBs. In addition, RAAS inhibitors partially neutralize the peripheral edema, which is a dose-limiting side effect of these CCBs. ${ }^{19}$ The combination of ARBs and TTDs was prescribed in almost $30 \%$ of the study population, the reason may be based on the fact that in long-term trials, combinations of an ARB or ACE inhibitor with a low dose Thiazide type diuretic has been found to be cause full additive BP reduction and has been classified as preferred combination. ${ }^{20}$ Diuretics initially reduce intravascular volume and activate the RAAS, leading to vasoconstriction as well as salt and water retention. In the presence of a RAAS inhibitor, this counter regulatory response is attenuated.

Among the co-prescribed drugs it was found that during the present study a large percentage of our patients were using proton pump inhibitors, antidiabetics, antiplatlet drugs and statins. Because most of our patients were given several drugs together and many of them especially Aspirin and Clopidogrel are known gastric irritants and proton pump inhibitors, the most commonly co prescribed drugs were given for gastric protection. Diabetes miletus was one of many common diseases that were found in our study population and the antidiabetics were prescribed for the treatment of the same. Antiplatlet drugs and statins were also commonly co prescribed along with many different antihypertensive drugs because they are found to have protective role in hypertension related cardiovascular diseases.

\section{CONCLUSION}

Present study represents the current prescribing trend for antihypertensive agents in this part of world. It implies that ARBs are the leading group of antihypertensive agents both when used singly or (and) in combination. The treatment of hypertension keeps on changing as newer drugs are being added and new guidelines are being put forth. Further studies focused on the rationale for choice of drugs based on demographic data, economic status, associated comorbid conditions and complications would 
give additional insights into prescribing patterns in hypertension. A therapeutic audit with more parameters of analysis to provide regular feedback to researchers and prescribers may encourage rational prescribing in hypertension.

Funding: No funding sources Conflict of interest: None declared

Ethical approval: Not required

\section{REFERENCES}

1. Kearney PM, Whelton M, Reynolds K, Muntner P, Whelton PK, He J, et al. Global burden of hypertension: Analysis of worldwide data. Lancet 2005;365 (9455):217-23.

2. Blood Pressure Lowering Treatment Trials Collaboration. Effects of ACE inhibitors, calcium antagonists, and other blood-pressure lowering drugs: results of prospectively designed overviews of randomized trials. Lancet. 2000;355:1955-64.

3. Staessen JA, Wang JG, Thijs L. Cardiovascular protection and blood pressure reduction: a metaanalysis. Lancet. 2001;358:1305-15.

4. Gupta N, Sharma D, Garg SK, Bhargava VK. Auditing of prescriptions to study utilization of antimicrobials in tertiary hospital. Indian J Pharmacol. 1997;29:4115.

5. Kapoor B, Raina RK, Kapoor S. Drug prescribing pattern in a teaching hospital. Ind $\mathbf{J}$ Pharmacol. 1985; 17:168.

6. Pradhan SC, Shewade DG, Shashindran CH, Bapna JS. Drug utilization studies. National Med J India. 1988;1:185.

7. Yuen YH, Chang S, Chong CK, Lee SC, Critchley JA, Chan JC. Drug utilization in hospital general medical outpatient Clinic with particular reference to antihypertensive and antidiabetic drugs. J Clin Pharm Ther. 1998;23:287-94.

8. Sutharson L, Hariharan RS, Vamsadhara C. Drug utilization study in diabetology outpatient setting of a tertiary hospital. Indian J Pharmacol. 2003;35:237-38.

9. Bakssas I, Lunde PKM. National drug policies: the need for drug utilization studies. Trends Pharmacol Sci. 1986; 7:331

10. Tiwari H, Kumar A, Kulkarni SK. Prescription monitoring of anti-hypertensive drug utilization at the
Panjab University Health Centre in India. Singapore Med. J. 2004;45:117-20.

11. Pittrow D, Kirch W, Bramlage P, Lehnert H, Höfler M. Patterns of antihypertensive drug utilization in primary care. Eur J Clin Pharmacol. 2004;60:135-42.

12. Lee PK, Li RKL, Chan JCN, Chang S, Lee SC. A prescription survey in a hospital hypertension outpatient clinic. Br. J Clin Pharmacol. 1997;44:57782.

13. Haribabu R, Reddy M, Vidyadhar S. Drug utilization of antihypertensive agents in an urban primary health care center in south India. Int $\mathbf{J}$ of Inno Pharma Res. 2012;3:244-6.

14. Elliott WJ, Meyer PM. Incident diabetes in clinical trials of antihypertensive drugs: a network metanalysis. Lancet. 2007;369:201-7.

15. European Society of Hypertension-European Society of Cardiology Guidelines Committee. J Hypertens. 2003;21(6):1011-53.

16. Pai PG, Shenoy J, Sanji N. Prescribing Patterns of antihypertensives drugs in a south Indian tertiary care hospital. Drug Invention Today. 2011;3:38-40.

17. Philipp T, Smith TR, Glazer R. Two multicenter, 8week, randomized, double-blind, placebo-controlled, parallel-group studies evaluating the efficacy and tolerability of amlodipine and valsartan in combination and as monotherapy in adult patients with mild to moderate essential hypertension. Clin Ther. 2007; 9:563-80.

18. Chrysant SG, Melino M, Karki S. The combination of olmesartan medoxomil and amlodipine besylate in controlling high blood pressure: $\mathrm{COACH}$, a randomized, double-blind, controlled, 8-week factorial efficacy and safety study. Clin Ther. 2008;30:587-604.

19. Gradman AH, Cutler NR, Davis PJ. Combined enalapril and felodipine extended release (ER) for systemic hypertension. Am J Cardiol. 1997;79:431-5.

20. Gradman AH, Kad R. Renin inhibition in hypertension. J Am Coll Cardiol. 2008;51:519-28.

Cite this article as: Hussain SS, Farhat SF, Zargar PA, Bali ZS. A descriptive study on drug prescribing pattern in hypertensive patients in a tertiary care teaching hospital. Int J Basic Clin Pharmacol 2017;6:2612-5. 